\title{
Pingelapese achromatopsia: correlation between paradoxical pupillary response and clinical features
}

\author{
G J Ben Simon, F A Abraham, S Melamed
}

Br J Ophthalmol 2004;88:223-225. doi: 10.1136/bjo.2003.027284

Aim: To evaluate the paradoxical pupillary constriction in darkness in patients with Pingelapese achromatopsia (PA), and to describe a connection between this phenomenon and the clinical features.

Methods: 27 patients with PA were examined. All underwent a full ophthalmic examination which included Snellen visual acuity and ophthalmoscopy. Colour vision examination was performed with Ishihara pseudoisochromatic plates and also with a colour plate consisting of five basic colours (red, green, purple, yellow, and orange). Paradoxical pupillary response was examined and documented with a special infrared video camera. Pupils' images were analysed using the Scion Image program and the ratio of pupil size in darkness to its size in light was calculated and recorded.

Results: Mean visual acuity was 20/400 (range 20/80-20/ 800 ). Colour vision examination showed a mean of 3.2 (SD 1.5) (range 1-5) of Ishihara colour plates, and 0.5 (0.75) (03) of basic colour plates. 23 patients (85\%) had paradoxical pupillary constriction in darkness. Mean dark/light ratio of pupillary area was 0.86 (range $0.5-1.6$ ). In patients with marked paradoxical pupillary constriction there was a significant correlation of visual acuity and Ishihara score. Conclusions: Clinical manifestations of achromatopsia include total colour blindness, low visual acuity (mean of $20 / 400$ ), horizontal pendular or rotatory nystagmus, and photophobia. Most patients have paradoxical pupillary constriction in darkness. When this response is brisk it seems to correlate with lower visual acuity and lower Ishihara score.

C omplete achromatopsia or rod monochromatism is a rare autosomal recessive disease characterised by total colour blindness, low visual acuity, nystagmus, and photophobia. The clinical features may be explained by nonfunctioning cones in the presence of normal rods. ${ }^{1}$ A unique form of the disease was identified in Pingelap, a tiny island in the Pacific part of the Eastern Caroline Islands of Micronesia. $^{2}$

In 1775 a typhoon named Liengkieki decimated most of the island population, leaving the remainder to die of hunger and only a minority of the original population survived. Consanguinity and the resultant undesirable homozygosity have brought on the high prevalence of this colour blindness in Pingelapese population.

It is estimated that nearly $6-10 \%$ of the Pingelapese population have achromatopsia, and as much as $30 \%$ are carriers. ${ }^{2-6}$ For comparison, in the general population achromatopsia is a very rare condition, affecting only $1: 20000-1: 50000 .^{78}$

Recently the defected gene of Pingelapese achromatopsia (PA) was mapped to chromosome 8q21-q22. ${ }^{10}$ A missense mutation (serine $\rightarrow$ phenylalanine) results in a defective $\beta$ subunit of cone photoreceptor cGMP dependent cationic channel, resulting in non-functioning cones. This mutation differs from another gene for achromatopsia, mapped to chromosome 2q11 (in an Iranian-Jewish population), where the $\alpha$ subunit of the cone photoreceptor cGMP dependent cationic channel is defective. ${ }^{11-14}$

A unique clinical feature of complete achromatopsia is paradoxical pupillary constriction to darkness. After exposure to bright light for 2-3 minutes and transfer to darkness, many patients with achromatopsia (rod monochromatism) will show pupillary constriction. This phenomenon (also know as Flynn phenomenon) is not unique to achromatopsia and can be found in dominant optic atrophy, Leber's congenital amaurosis, congenital stationary night blindness, old bilateral optic neuritis, congenital nystagmus, strabismus, and amblyopia. ${ }^{15-19}$

The purpose of this study was to evaluate the paradoxical pupillary response in PA and describe the correlation between this response and clinical manifestations.

\section{PATIENTS AND METHODS}

Twenty seven patients (nine men, 18 women, mean age 20 (SD 13) years) were examined; 17 from Mahnd village-a small Pingelapese village in Pohnpei (central island of Federated States of Micronesia) and 10 from Pingelap atoll.

All patients underwent a full ophthalmic examination, which included Snellen visual acuity, slit lamp examination (in Pohnpei), and ophthalmoscopy. Colour vision examination was performed using two methods: Ishihara pseudoisochromatic plates and a colour plate consisting of five basic colours (red, green, purple, yellow, and orange). Patients were asked to identify the numbers (or follow with their finger) in the Ishihara plate, and to identify the colours in our colour plate. Nystagmus was evaluated by clinical impression and graded +1 to +3 according to velocity and amplitude ( 1 , minimal; 3, maximal).

In order to examine paradoxical pupillary response patients were exposed to bright light for 3 minutes. Pupil size (in light) was evaluated and documented with a video camera (Sony, Digital Handycam, DCR-PC101E). After a quick change to total darkness pupils were photographed with an infrared video mode of the same camera. The second pupil photograph in darkness was captured from the same distance and viewing angle as the pupil photograph in light.

Pupil images were analysed using Scion Image for Windows. Images were viewed in threshold configuration (fig 1) and the exact area of the pupil was measured in square pixels. The ratio of pupil size in darkness to pupil size in light was calculated and recorded (marked dark/light ratio, no units).

\section{Statistical analysis}

Comparison of clinical characteristics between men and women was performed with independent samples Student's $t$ test. Correlation between dark/light ratio, age, nystagmus 


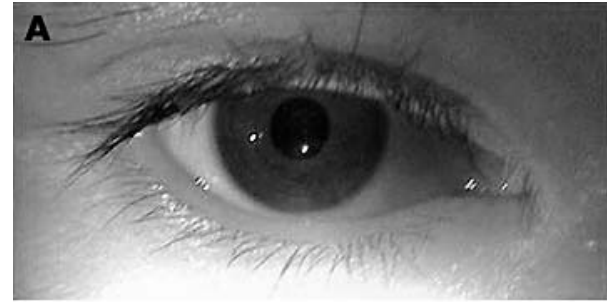

B

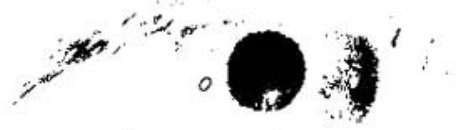

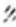

Figure 1 Pupil image as taken with the video camera (A), and pupil image in threshold configuration using Scion Image for Windows (B). Pupil area was measured in square pixels, and dark/light ratio was calculated and recorded.

rate, number of identified Ishihara pseudoisochromatic colour plates, and $\log$ MAR visual acuity was assessed using Pearson correlation. Linear regression analysis was used to estimate the probability of paradoxical pupillary response and numerical variables such as visual acuity or colour vision. Statistical analysis was performed using SPSS program.

\section{RESULTS}

Twenty seven patients (nine men, 18 women, mean age 20 (SD 13) years) were examined. Mean visual acuity was 20/ 400 (range 20/80-20/800). Colour vision examination showed a mean of 3.2 (1.5) (range 1-5) Ishihara colour plates identified, and $0.5(0.75)$ (range $0-3$ ) with our basic colour plates.

All patients showed horizontal pendular or rotatory nystagmus with clinical grading of 2 (0.6) (range 1-3).

Ophthalmoscopy (all patients) and slit lamp examination (in Pohnpei) were normal.

Twenty three patients (85\%) had paradoxical pupillary constriction in darkness (fig 2). Mean dark/light ratio of pupillary area (in square pixels) was 0.86 (range 0.5-1.6). Three patients had dark/light ratio $>1$, and only one patient was not measured.

Taking all patients, paradoxical pupillary constriction in darkness had no significant correlation with all parameters

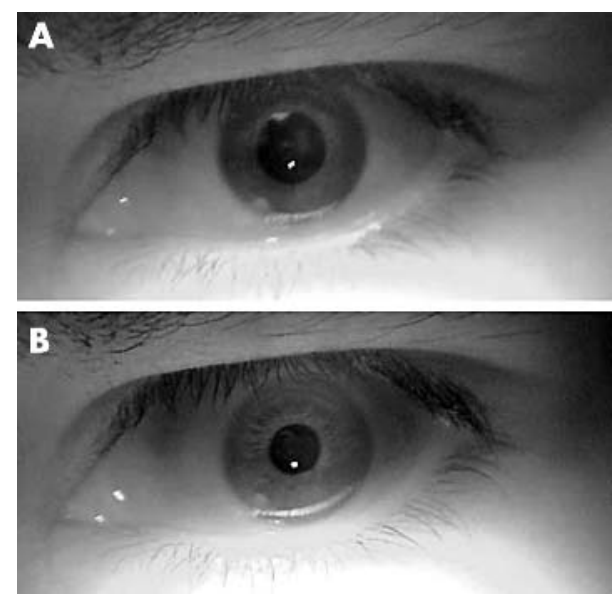

Figure 2 Paradoxical pupillary constriction in darkness. (A) Dilated pupil after exposure to bright light for 3 minutes. (B) Pupillary constriction immediately after exposure to total darkness. measured such as age, $\log \mathrm{MAR}(\mathrm{VA})$, Ishihara colour plates, and grade of nystagmus. However, there was a trend for correlation between $\log$ MAR visual acuity to Ishihara colour plates $(\mathrm{p}=0.1)$.

Regression analysis including patients with dark/light $\leqslant 0.8$ (marked pupillary constriction, 10 patients) showed a significant correlation between $\log M A R$ visual acuity and Ishihara colour plates $(\mathrm{R}=0.713, \mathrm{p}=0.021)$ (fig 3). Of those, six patients with dark/light $\leqslant 0.7$ showed significant correlation between dark/light ratio and Ishihara colour plates $(\mathrm{R}=0.89, \mathrm{p}=0.018)$.

No differences were noticed between men and women in clinical features or tested parameters.

\section{DISCUSSION}

In this work we had a rare opportunity to examine the unique population with PA in their native land. Clinical manifestations of the disease are quite homogeneous, manifested with low visual acuity (mean 20/400), horizontal pendular or rotatory nystagmus and photophobia, total colour blindness as implied by inability to identify our basic colour plates and low score in Ishihara pseudoisochromatic plates. These clinical manifestations have been described by others ${ }^{12}$ but unlike their report, which claimed no identification of Ishihara colour plates by all patients, we found a mean of three colour plates correctly identified. Also, in our study we report for the first time the occurrence of paradoxical pupillary constriction in darkness in PA and its correlation with clinical manifestations of the disease.

Paradoxical pupillary constriction to darkness, originally described by Flynn et $a l^{18}$ is a unique, poorly explained phenomenon which is associated with several eye diseases, most of them characterised by low visual acuity and nystagmus. It has been described in dominant optic atrophy, Leber's congenital amaurosis, congenital stationary night blindness, old bilateral optic neuritis, congenital nystagmus, strabismus, and amblyopia..$^{15-19}$

Other investigators ${ }^{17-19}$ who studied paradoxical pupillary constriction have noticed the phenomenon to occur only in a few patients with classic achromatopsia or in congenital stationary night blindness.

We have shown that $85 \%$ of patients with PA had paradoxical pupillary constriction in darkness, with a mean dark/light ratio of 0.86 (range 0.5-1.6). It is important to notice that a response of dark/light $=1$ is also abnormal since the pupil is not dilating in darkness. Only three patients had dark/light $>1$ which can be ascribed to technical difficulties while measuring those patients.

The exact mechanism of paradoxical pupillary constriction in darkness is not fully understood. It is speculated that the rods send a "bleaching signal" after strong illumination (for 3 minutes as performed in our patients) and immediate transfer to darkness, this signal over-rules the malfunctioning cone system, resulting in paradoxical pupillary constriction. ${ }^{19}$

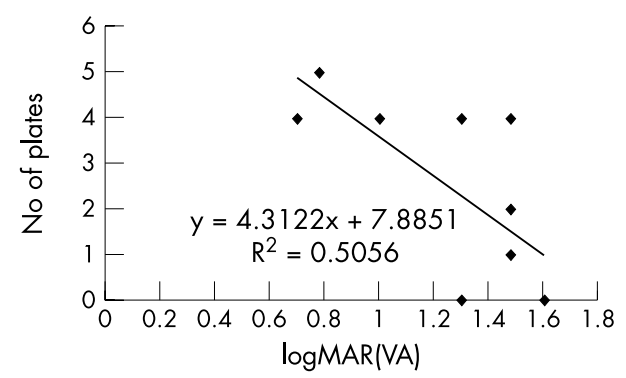

Figure 3 Correlation between $\log M A R(V A)$ and Ishihara colour plates in patients with marked pupillary constriction (dark/light $\leqslant 0.8$ ). 
The isolated population in Pingelap allows a very accurate evaluation of this genetic disorder. Interestingly, despite their difficulty in distinguishing colours, most patients do recognise different colours by their different grey tones. Consequently, most of them lead normal daily lives and are an integral part of their community. As one patient with PA was quoted: "We don't just go by colour, we look, we feel, we smell, we know-we take everything into consideration, and you just take colour!"

In summary, in this study performed under rigid field conditions, we describe the clinical manifestations of PA in 27 patients. In addition, we report for the first time on the occurrence of paradoxical pupillary constriction in darkness in the majority of these patients and its correlation to visual acuity and Ishihara colour vision score.

\section{ACKNOWLEDGEMENTS}

We would like to thank the government of Federated States of Micronesia, and the people of Pohnpei and Pingelap for their assistance, collaboration, and hospitality.

\section{Authors' affiliations \\ G J Ben Simon, F A Abraham, S Melamed, The Goldschleger Eye Institute, Sheba Medical Center, Tel-Hashomer, Israel, 52621}

Correspondence to: Guy J Ben Simon, MD, The Goldshcleger Eye Institute, Sheba Medical Center, Tel Hashomer, Israel 52621; guybs@barak-online.net

Accepted for publication 1 July 2003

\section{REFERENCES}

1 Sharp LT, Nordby K, In: In: Hess RF, Sharp LT, Nordby K, eds. Night vision: basic, clinical and applied aspects. Cambridge: Cambridge University Press, 1990:253-89.
2 Brody JA, Hussels I, Brink E. Hereditary blindness among Pingelapese people of Eastern Caroline Islands. Lancet 1970;1:1253-17.

3 Sheffield VC. The vision of typhoon lengkieki. Nat Med 2000;6:746-7.

4 Carr RE, Morton NE, Siegel IM. Achromatopsia in Pingelap islanders: study of a genetic isolate. Am J Ophthalmol 1971;72:746-56.

5 Hussels IE, Morton NE. Pingelap and Mokil atolls: achromatopsia. Am J Hum Genet 1972;24:304-9.

6 Sacks O. The island of the colorblind. New York: Vintage Books, Random House, 1998

7 Francois J. Heredity in ophthalmology. St Louis: Mosby, 1961:198.

8 Jager W. Genetics of congenital colour deficiencies. In: Autrum VH, Jung R, Lowenstein D, eds. Handbook of sensory physiology. Heidelberg: Springer, 1972:625-69.

9 Winick JD, Blundell ML, Galke BL, et al. Homozygosity mapping of the achromatopsia locus in the Pingelapese. Am J Hum Genet 1999:64:1679-85.

10 Sundin OH, Yang JM, Li Y, et al. Genetic basis of total colourblindness among the Pingelapese islanders. Nat Genet 2000;25:289-93.

11 Kohl S, Marx T, Giddings I, et al. Total colourblindness is caused by mutations in the gene encoding the $\alpha$-subunit of the cone photoreceptor cGMP-gated cation channel. Nat Genet 1998;19:257-9.

12 Arbour N, Zlotogora J, Knowlton R, et al. Homozygosity mapping of achromatopsia to chromosome 2 using DNA pooling. Hum Mol Genet 1997:6:689-94.

13 Wissinger B, Jagle $\mathrm{H}$, Kohl S, et al. Human rod monochromacy: linkage analysis and mapping of a cone photoreceptor expressed candidate gene on chromosome 2q11. Genomics 1998;51:325-31.

14 Nathans J, Thomas D, Hogness DS. Molecular genetics of human color vision: the genes encoding blue, green and red pigments. Science 1986;232:193-202.

15 Ohmi G, Gottlob I, Wizov SS, et al. Rod monochromatism and blue cone monochromatism: pupillary, accommodative and convergence reactions to darkness. Binocul Vis Strabismus 1999;14:291-8.

16 Jacobson DM, Thompson HS, Bartley JA. X-linked progressive cone dystrophy. Clinical characteristics of affected males and females carriers. Ophthalmology 1989;96:885-95.

17 O'Connor PS, Tredici TJ, Ivan DJ, et al. Achromatopsia. Clinical diagnosis and treatment. J Clin Neuro-ophthalmol 1982;2:219-216.

18 Flynn JT, Kazarian E, Barricks M. Paradoxical pupil in congenital achromatopsia. Int Ophthalmol 1981;3:91-6.

19 Barricks ME, Flynn JT, Kushner BJ. Paradoxical pupillary responses in congenital stationary night blindness. Arch Ophthalmol 1977:95:1800-4.

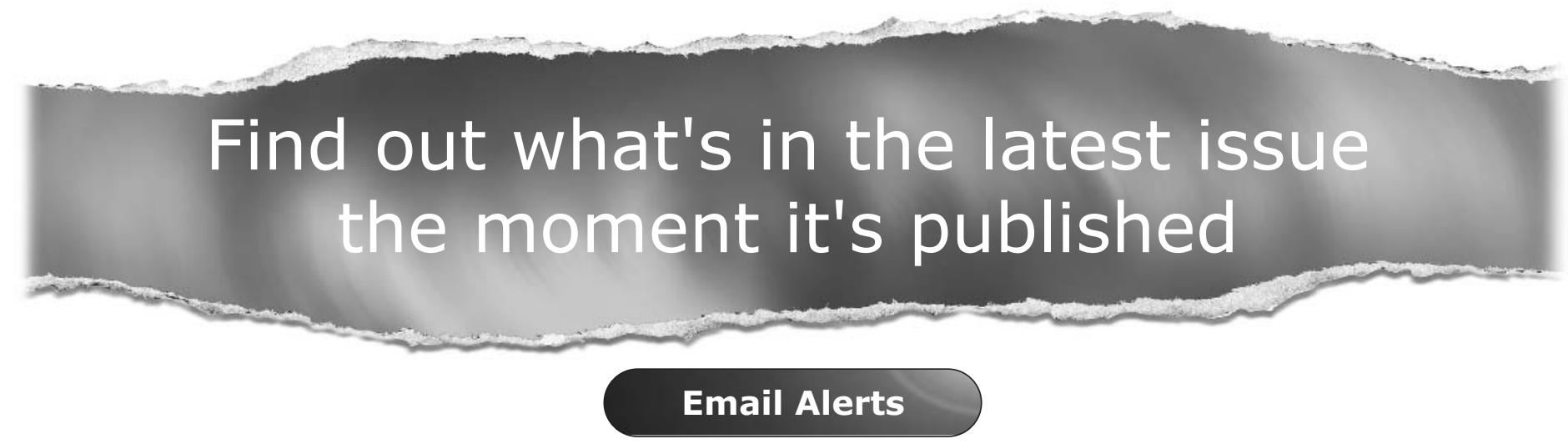

Sign up to receive the table of contents by email every month. You can select from three alerts:

Table of Contents (full), TOC Awareness (notice only); British Journal of Ophthalmology related announcements. 